\title{
Is there a perceptual relation?
}

Tim Crane

University College London

\section{Introduction}

P.F. Strawson argued that 'mature sensible experience (in general) presents itself as ... an immediate consciousness of the existence of things outside us' (1979: 97). He began his defence of this very natural idea by asking how someone might typically give a description of their current visual experience, and offered this example of such a description: 'I see the red light of the setting sun filtering through the black and thickly clustered branches of the elms; I see the dappled deer grazing in groups on the vivid green grass...' (1979: 97). In other words, in describing experience, we tend to describe the objects of experience - the things which we experience - and the ways they are when we are experiencing them.

Some go further. According to Heidegger,

We never ... originally and really perceive a throng of sensations, e.g., tones and noises, in the appearance of things...; rather, we hear the storm whistling in the chimney, we hear the three-engine aeroplane, we hear the Mercedes in immediate distinction from the Volkswagen. Much closer to us than any sensations are the things themselves. We hear the door slam in the house, and never hear acoustic sensations or mere sounds. (Heidegger 1935: 156; quoted by Smith 2002: 105) 
Whether or not we all want to agree with Heidegger that we have immediate consciousness of the difference between a Volkswagen and a Mercedes, many of us will agree with him that in normal perceptual experience the 'things themselves' seem much closer to us than a 'throng of sensations'. This does not by itself imply that we are not in any way aware of a throng of sensations in perceptual experience.

Heidegger only says that we are not originally and really aware of them; even if the things themselves are 'closer' to us than sensations, this still implies that the sensations are somewhere to be found, so to speak, in the experiential neighbourhood. It is obvious that perceptual experience is sensory in a way in which thought is not, and a theory of perception has to make room for this.

Nonetheless, in recent years a number of philosophers have argued that all we are aware of in experience - and all we can be made aware of by introspecting an experience - are the 'things themselves': the everyday objects of experience and their properties. On this view, known as 'representationalism', introspection of a perceptual experience never reveals awareness of any properties of the experience itself or of what Heidegger calls a 'throng of sensations'. The opposing view holds that although we are aware in perceptual experience of things outside us, introspection of an experience can reveal awareness of properties of the experience itself. One reason someone might hold this is because they think experience always involves the instantiation of intrinsic, non-representational 'qualitative' properties, known as qualia. ${ }^{1}$ I will call this view the 'qualia theory'. The qualia theory combines rejection of representationalism with an explanation of that rejection in terms of qualia.

\footnotetext{
${ }^{1}$ For defences of the qualia theory, see Peacocke 1983; Shoemaker 1990; Block 1996, 1997 and forthcoming. For defences of representationalism, see Harman 1990; Tye 1992, 1995 and 2000 ; Thau 2002; Hilbert and Kalderon 2000; Byrne 2001. Two important discussions which defend neither side as described here are Martin 2002 and Stoljar forthcoming.
} 
Ned Block has called the dispute between representationalism and the qualia theory the 'greatest chasm in the philosophy of mind' (Block 1996:19). The main purpose of this paper is to dispute this claim of Block's. I will argue that as far as the philosophy of perception is concerned, the dispute over the existence of qualia is not very significant at all. It may be that in other parts of philosophy of mind - for example, in the debate about the physicalistic reduction of consciousness - the existence of qualia is a chasm-creating question. (Actually, I doubt this too; but I will not argue for it in any detail here. ${ }^{2}$ ) My concern here is just with philosophical debates about perception: my claim will be that as far as the philosophy of perception is concerned, the question of qualia is not an important question.

The debate to which Block is referring is often discussed in terms of whether experience is 'transparent' or 'diaphanous'. But, as we shall see in section 2, whatever is correct in the idea of the transparency of experience cannot establish the truth of representationalism. In fact, it seems to me that it is relatively easy to show that representationalism is false. This rejection of representationalism does not touch the main problems of perception, although the reasons for the rejection point towards what these real problems are. Accordingly, in sections 3-5 of this paper, I will argue that there is a large chasm in the philosophy of perception, but that it is created by the dispute about whether experience is relational. It is this dispute - between 'intentionalists' and 'disjunctivists' - which concerns the most recalcitrant problems

\footnotetext{
${ }^{2}$ But let me give a brief indication of my reasons for this doubt. Many people express the problem of consciousness in terms of the notion of qualia. Chalmers (1996) and Block (2003) put the problem in this way. Yet while Block thinks there must be a naturalistic, physicalistic account of qualia, Chalmers thinks that there cannot be. So their dispute is not over the existence of qualia, but over whether they can be physicalistically explained. To this it may be said, as Byrne (2001) does, that if there were no qualia and if we therefore had a representational account of consciousness, this would be one step on the road to a physicalistic reduction of consciousness. But if this were the case, it would still be necessary to give a physicalistic explanation of why certain representations were conscious and others were not, and - 'Higher-Order Thought' views notwithstanding - representationalist accounts of consciousness have made no more progress with this question than qualia-based accounts have with their parallel question. So it seems to me that in this case too, it is unlikely that the existence of qualia is the kind of issue in relation to which the real chasm develops.
} 
of perception. The major theories of perception in contemporary analytic philosophy line up on either side of this dispute. I will argue that when seen in this context, the debate about the existence of qualia is a relatively minor side dispute among intentionalists, rather than a major chasm in the philosophy of perception.

My aim in demonstrating this is not simply negative. It is also an attempt to show what it means to say that perception is intentional, and therefore what the essence of an 'intentionalist' approach to perception is - something which I think has not been very well understood in recent philosophy of perception. A correct understanding of intentionalism about perception must derive from a correct understanding of the problems of perception. But before explaining this, I will begin with a few remarks about the transparency of experience.

\section{Transparency}

What recent philosophers call the 'transparency' or 'diaphanousness' of experience is the idea that that reflection on what it is like to have an experience does not reveal properties of experiences themselves, but only of their objects. As a number of writers have pointed out (Martin 2002; Siewert 2003: 18; Stoljar forthcoming), there are really two claims here: (i) we are aware of the objects of experience, and (ii) we are not aware of features of experiences themselves. In his expositions of the transparency idea, Michael Tye makes both claims. First, the positive claim about what we are aware of:

When one tries to focus on [an experience of blue] in introspection one cannot help but see right through it so that what one actually ends up attending to is the real colour blue. (Tye 1992:160) 
And second, the negative claim about what we are not aware of:

When we introspect our experiences and feelings, we become aware of what it is like for us to undergo them. But we are not directly aware of those experiences and feelings; nor are we directly aware of qualities of experience. (Tye 2000:

51)

Plausible as these two claims might initially seem, I think it is easy to show that they are not true.

What is right about the first claim is that introspection does typically reveal the objects of perceptual experience, and that we typically describe our experiences in terms of these objects, as Strawson pointed out. But it does not follow from the fact that we typically describe our experience in this way, that in every case in which we introspect an experience of (e.g.) something blue, we 'see right through' to the real colour blue. For if this were so, then all introspectible experiences would involve relations to real objects and real instances of properties, like colours (assuming, for the sake of argument, that colours are real properties of external objects). But not all experiences do involve relations to real objects or property instances: one can have hallucinatory or otherwise deceptive experiences which involve no such relations. ${ }^{3}$ So it cannot be true that in every case of perceptual experience 'the qualities to which we have direct access ... are qualities of external things' (Tye 2000: 51).

Tye's response to this is to say that what one is aware of when hallucinating are 'specific aspects of the content of the experience'. And since he believes that

\footnotetext{
${ }^{3}$ I am putting to one side here (and in section 3 ) the view that in a hallucination we are aware of uninstantiated universals, a view defended by Johnston (2004). The view demands further discussion.
} 
one's state of mind when hallucinating is the same as when one is perceiving, this is what we are aware of when we introspect our perceptions as well as our hallucinations.

What is meant by the 'content of experience'? This is where we move into more specific areas of theories like his. Philosophers like Tye think that perception is a propositional attitude, and that like belief, it has a content which is expressed by the 'that'-clause in ascriptions of perceptual experiences. The content of perception is therefore a proposition. Taking what Tye says literally, then, he is saying that in introspection we are aware of aspects of propositions. I will discuss this view in section 4 below. But notice here that we seemed already to have moved away from claims about what is obvious about perception: the immediate initial appeal of the idea that all we are aware of in perception are things like the wind in the chimney and the blue of the sea starts to crumble in our hands. If we are merely hallucinating something blue, then blueness is not instantiated at all. But that means that there is no instance of the real colour blue for us to be aware of in introspection. Even if we are aware of the fact that our experience represents something blue, this does not by itself mean that there is anything blue which we are aware of.

What about the second, negative, claim? It seems initially plausible that in normal perceptual experience one is not aware of features of one's experience. I started this paper with the observation that perceptual experience seems to be an awareness of the world, of the things themselves. So it might seem equally natural to say that in perceptual experience I am not aware of qualities of my experience; I have the experience, and in having the experience, I become aware of the world.

But why should it never be true that one can be aware of qualities of one's experience? Is it impossible to take what J.J. Gibson once called the 'painterly 
attitude' to visual experience, and attend to the way the experience itself is, as opposed to the features of the things themselves? It may still be true in this kind of case that 'the public, mind-independent objects of perception and their features are not banished from one's attention just because one shifts one's interest from how things are in the environment to how things are experientially' (Martin 2002: 384). But this does not imply that one is not able to attend to how things are experientially. Tye agrees with this; his view is that 'we attend to the external surfaces and qualities and thereby we are aware of something else, the "feel" of our experience' (2000: 51-2). You become aware of how your experience phenomenally is (its 'feel') by attending to what is represented. I think we should agree with Tye that this is often - or even usually - the case. But the next question is whether there is any situation in which you can become aware of how your experience is by attending to the experience itself rather than by attending to its objects (e.g. 'external surfaces and qualities'). For after all, the question for a theory of perception is surely not how often we are aware of things of a certain kind, or (pace Kind 2003) how difficult it is to be aware of such things; the question is whether we are ever aware of things of that kind. So if we are ever directly aware of features of our experience which are not features of the objects of experience - or features which these objects are represented as having - then Tye's negative claim is false: we can be 'directly aware of qualities of experience'.

Brief reflection on some everyday phenomena seems to reveal many cases of such awareness. I remove my glasses and things seem blurry. Introspecting this experience, blurriness does certainly seem to be instantiated somewhere. But does it seem to be instantiated in the familiar objects of experience? Surely this need not be the case: it need not seem as if these objects are themselves blurry. When I say that 
'everything seems blurry' I don't mean that it seems as if the things around me are blurry - any more than when I say that 'everything is dark in here' I mean that it seems as if the things around me are dark ('the chairs are dark, the table is dark...'). What I mean is that I am experiencing things in a blurry way. Isn't this a straightforward case of where one can be 'directly' aware of an aspect of one's experience which is not an aspect of the objects of experience? It is natural to say that I am aware of blurriness; but I am not aware of blurriness by being aware of any other properties; and blurriness does not seem to be a property of objects of experience.

Tye's response to cases like this appeals again to representation. He claims that there are cases when one experiences something as blurry, when one's visual experience 'comments inaccurately on boundaries': it 'says' that the boundaries of things are fuzzy (2000). We can concede that there are cases like this; but they are not relevant. The relevant case is one in which one experiences things blurrily without experiencing them as blurry. About this kind of case, Tye says that one 'simply loses information ...one undergoes sensory representations that fail to specify where the boundaries and contours lie' (2000). In this kind of case, then, the experience does not 'say' incorrectly that things are blurry; it just fails to specify how things are in enough detail.

But how does this bear on the question of whether one can be 'directly aware of qualities of experience'? Let's accept that Tye is right that the experience underspecifies the perceived environment. The phenomenal upshot of this, everyone agrees, is that things are seen blurrily. So blurriness does seem to be a property of some kind, which does seem to be instantiated somewhere. Unlike when things are seen as blurry, it doesn't seem to be instantiated by the objects of experience. So what is wrong with saying that it is instantiated (in some way) in the experience itself? 
Moreover, since I do not have to make myself aware of blurriness by first making myself aware of other things - the awareness of blurriness comes along all together with the awareness of everything else - introspection of seeing blurrily does seem to reveal a case of being 'directly aware of qualities of experience' in an uncontroversial sense of that phrase.

Neither part of the transparency claim, then, is true without qualification. To be sure, it is generally true that the things we see directly are ordinary things and their properties: and in this sense we normally 'see through' experiences to the real world objects and properties themselves. But if subjectively indistinguishable hallucinations are possible, then this is not always true. Likewise, it is generally true that we are not directly aware of properties of experiences themselves. But there also seem to be uncontroversial cases where we are, and it is not obvious why we should argue them away.

If representationalism is committed to the transparency theses, then it is false. But this fact does not itself imply the qualia theory. For the qualia theory as defined above is not simply the denial of representationalism; rather it denies representationalism and gives an explanation of this denial in terms of qualia (intrinsic, conscious, non-representational properties of experience). ${ }^{4}$ I will return to the qualia theory in section 6 .

Nonetheless, our brief investigation of transparency has brought to light two questions at the heart of the traditional philosophical debates about perception. Reflection on the positive transparency claim raises the question: how should we give an account of what we experience when we hallucinate something? And reflection on the negative transparency claim raises the question: how should we give an account of

\footnotetext{
${ }^{4}$ Sceptics about qualia will not find this definition of 'qualia' very illuminating; while I am sympathetic to this scepticism, I will assume this standard characterisation in what follows for the sake of argument.
} 
the properties which seem to be instantiated in experience when those properties are not - and do not even seem to be - properties of external objects? This second question leads us back to the argument from illusion; while the first leads us to the argument from hallucination.

\section{The problems of perception}

The traditional arguments from illusion and from hallucination deserve separate treatment. Some philosophers (occasionally following Austin 1962) have expressed scepticism about whether these arguments are still worth discussing. I will not target such scepticism directly, but instead I will rely on the recent defences of the arguments by Howard Robinson (1994) and A.D. Smith (2002).

First, the argument from illusion. An illusion here we can define with Smith as 'any perceptual situation in which a physical object is actually perceived, but in which that object perceptually appears other than it really is' (Smith 2002: 23). So illusion in this sense need not involve deception. The argument from illusion says that when one is subject to an illusion (in this sense) then one is experientially aware of something's having a quality, $F$, which the real object being perceived does not actually have. It is then argued that when one is experientially aware of something's having a sensory quality $F$, then there is something of which one is aware which does have quality $F$ (this claim is what Robinson (1994: 32) calls the 'Phenomenal Principle'). Since the

real object in question is, by hypothesis, not $F$, then it follows that one is not aware of this real object after all; or if one is, one is aware of it only 'indirectly' and not in the direct, unmediated way in which we normally think we are aware of objects. Hence this normal belief - sometimes called 'naïve realism' or 'direct realism' - is false. The standard traditional alternative to direct realism is the sense-datum theory, which says 
that the thing of which one is aware (or immediately or directly aware) is not a public physical object but an object (a 'sense-datum') whose existence depends on the existence of the experience. It is this object which has the quality $F$ which the real object does not have.

The argument from illusion is often rejected because the Phenomenal Principle is rejected: why should it be that whenever anyone is aware of something as having a property, there really is something which has this property? This is not true for the case of belief or judgement, for example: that when someone consciously judges that something has a property, then there is something which has this property. Indeed, it is often said that perception, like belief, is a form of representation of the world, and it not true of representations in general that when a representation represents that something has a property, there is something which does have that property. To claim that it must be otherwise in the case of perceptual experience is to beg the question in favour of sense-data.

Nonetheless, even if one rejects sense-data, one might hold that the quality $F$ of which one is aware in having an illusory experience is not a quality of any object of experience, but is rather a quality of the experience itself. This is the essence of the 'abverbial' conception of experience (Chisholm 1957; Ducasse 1942). When one experiences a blue object, this is understood as experiencing bluely - where the adverb 'bluely' modifies, and therefore attributes a property to, the experience. The idea that perceptual experience involves this kind of property of experience resembles the central claim of the qualia theory. Like the adverbial theorist, the qualia theorist need not say that the quality predicated of an experience is the same kind of quality as the quality predicated of the object of experience. Instead they might say, with Peacocke (1983 chapter 1), that while objects are blue, regions of the visual field are 
blue', where being blue' is the way the visual field is when a blue object is perceived in normal circumstances. I will return to the relation between the adverbial theory and the qualia theory at the end of this paper.

The argument from hallucination can be formulated as follows. Perceptual experience in all five senses seems intuitively to be a relation to mind-independent objects of experience. But it seems possible for there to be an experience which seems just like a perception of a real mind-independent object but where there is no real mind-independent object being perceived. This is what we shall call a hallucination. If a hallucination is a mental state of the same fundamental kind as the perception, then it turns out that perceptual experience isn't a relation to a mind-independent object after all. The conclusion of this bit of the argument is that our pre-theoretical conception of perception as a relation to mind-independent objects must be wrong. So what should we say instead? A traditional answer again is that perception is instead a relation to sense-data, construed as mind-dependent entities (Broad 1923; Price 1932). This answer has been widely criticised and I will not add to these criticisms here.

But other answers are possible. One is to deny that perception is essentially a relation at all. Rather, perception is a representation of the world; and as we saw above, it is not generally true that if $\mathrm{X}$ represents $\mathrm{Y}$, then $\mathrm{Y}$ must exist. So a perceptual representation need not essentially involve a relation to what it represents. This is the intentionalist conception of perception, which I will discuss in section 4 below. Another response to the argument is to deny that a perception and a subjectively indistinguishable hallucination are mental states or events of the same fundamental kind. Perception is a genuine relation to the world, but hallucination is a mere appearance or mere representation; and there is no more fundamental kind of mental state ('perceptual experience') to which they both belong. This is the 
disjunctivist conception of perception, to be discussed in section 5. The contrast between these two views is well described by John Campbell as the contrast between the 'Relational' and 'Representational' views of experience (Campbell 2002: 114-24).

Looked at from a sufficient distance, the arguments from illusion and hallucination have a similar form. They both present a conflict between an apparently manifest or obvious fact about perceptual experience, and a kind of perceptual error or misperception of the world. The apparently obvious fact is that experience seems to be a relation to its objects. From the subject's point of view, experience seems to be a kind of 'openness to the world': how things are in perceptual experience is partly determined by how things are with the objects of experience. And how things are in an experience is partly determined by how the objects of experience are at the time at which one is experiencing them. This seems an obvious apparent difference between perception and thought: what you can think about does not seem to be constrained, in general, by the existence and characteristics of the objects of thought; what you can perceive, however, does. (This point is not intended to presuppose internalism about thought; even if externalism were true, this contrast between perception and thought would stand. $)^{5}$

The importance of this apparent relationality is especially obvious in the case of the argument from hallucination, which can be construed as a reductio ad absurdum of the idea that perception is a relation to mind-independent objects. But it is also implicit in the central premise of the argument from illusion, Robinson's Phenomenal Principle. Recall that this principle says that when a subject has a sensory experience as of something being $F$, then there is something which is $F$ which the subject is experiencing. In other words, an experience of something's being $F$ must be

\footnotetext{
${ }^{5}$ Nor is the issue whether ordinary perceptual verbs, like 'sees that...' are factive. All participants to this dispute can agree with this, but this semantic point is independent of all the substantive issues raised by the problem of perception.
} 
or involve a relation to an instantiation of $F$-ness. Faced with the apparent presence of $F$-ness even when the object perceived is not $F$, the sense-datum theorist says that $F$ ness is a property of a sense-datum. The adverbialist responds to this by saying that the experience has the property of being a sensing $F$-ly. This property is not $F$-ness: experiences of blue things are not themselves blue. But nonetheless even the adverbial theory holds that experience must be explained in terms of the instantiation of phenomenal mental properties of a certain kind.

Our reflections on the inadequacy of the transparency thesis led us back to the traditional problem of perception. The essence of this problem, it seems to me, is how to account for the apparent relationality of perception, given the possibility of illusion and hallucination. In other words, is there really a perceptual relation, as there seems to be? The three dominant theories respond to this in different ways: the sense-data theory and the disjunctivist say that there is a perceptual relation, but while the sensedata theorist says that in cases of illusion and hallucination the relatum is not an ordinary mind-independent object, the disjunctivist says that genuine perception is a relation to ordinary mind-independent objects, but that there is no common fundamental kind of state - 'perceptual experience' - present in cases of genuine perception, which is a relation to a mind-independent object, and illusion and hallucination, which are not. The intentionalist theory of perception in effect denies that perceptual experience is a relation at all. In the next two sections I will consider this opposition between the intentionalist and disjunctivist theories of perception, before returning to the question of qualia in section $6 .^{6}$

\section{Intentionality}

\footnotetext{
${ }^{6}$ It will be obvious to anyone familiar with Mike Martin's work on perception (especially 2000, 2002, 2003) how much the discussion in this section is indebted to him.
} 
We saw that a natural response to the arguments from illusion and hallucination was to deny what Robinson calls the Phenomenal Principle. And the reason to deny it in the case of perceptual experience is because experience seems an obvious case of representation of the world, and principles like this are not generally true of representations. So we are not obliged to accept the Phenomenal Principle. To deny the Phenomenal Principle is to hold, then, that the existence of a perceptual experience does not entail the existence of its object. This implies straightforwardly that experiences are not relations to the objects of experience. ${ }^{7}$

It has traditionally been part of the concept of intentionality - the mind's directedness upon its objects - that the existence of an intentional state does not entail the existence of its object and that therefore intentionality is not a relation in the sense just specified (see Brentano 1874: 271-2; Husserl 1900/1901:216; Anscombe 1965). It is for this reason that I call the non-relational, representational conception of experience intentionalism. I will also assume, along with the philosophical orthodoxy, that if a condition or property is not relational then it is intrinsic. So intentionality in this traditional sense must be an intrinsic feature of mental states or acts. And intentionalism therefore says that the intentionality of perception is intrinsic to perceptual experiences themselves.

This traditional understanding of intentionality - that it is not a relation, and therefore an intrinsic feature of states of mind - has been obscured in recent discussion by a number of other ideas. One is externalism, which I will discuss below. Another is the fact that qualia are typically characterised as intrinsic features of states of mind, in contrast with intentional features which are then supposed to be relational. Intentional properties are sometimes said to be relational because intentionality is

\footnotetext{
${ }^{7}$ Assuming, of course, that the objects of hallucinations are not non-existent real objects. See Smith (2002: chapter 9) for an illuminating discussion of this kind of view.
} 
understood functionally, in terms of 'relations to other states of mind'. But in fact this is not an adequate understanding of functionalism - since many of these 'relations' are only dispositional in nature, and dispositions clearly are not relations to their manifestations - and it would in any case beg the question against a functionalist account of qualia, such as that presented by Shoemaker (1975).

Yet another reason why intentional properties are thought to be relational is that they are supposed to involve relations to 'intensional entities' such as propositions. In a recent paper, Daniel Stoljar introduces a thesis about the phenomenal character of experience which he calls the relational thesis: 'the phenomenal character of an experience is wholly determined by the objects that one is related to in having the experience'. Put this way, Stoljar's thesis sounds the same as Campbell's relational view of experience: 'the phenomenal character of your experience, as you look around the room, is constituted by the actual layout of the room itself' (2002: 116). But it turns out that Stoljar means something different, since the view he calls 'intentionalism' (which is in fact Tye's representationalism) holds this relational thesis too:

According to intentionalism ... to have an experience is in effect to stand in a relation to some intentional object - say a property or proposition. ... the relational thesis tells us that the phenomenal character of the experience is determined by features of the proposition or property that is the intentional object of the experience. (Stoljar forthcoming: section 2.5)

But we should distinguish the propositional content of an experience - the way it represents the world as being - from its intentional object. The intentional object of an 
intentional state or act is traditionally understood as what the intentional act is about or directed at. Hence the intentional object of a perceptual experience is what it is that is experienced. If I see a rabbit, the rabbit is the intentional object of my experience. My experience may also have the propositional content that there is a rabbit running through the field. But I do not see such propositional contents or propositions; I see rabbits and fields. For this reason, even if perceptual experience should be analysed in terms of relations to propositions, it is at best misleading and at worst absurd to say that these propositions are the intentional objects of experience in the normal understanding of this phrase.

In treating an intentional theory of perception as committed to what he calls the relational thesis - with 'object' understood to apply to propositions as well as ordinary objects - Stoljar conflates two ideas: relations to intentional objects and relations to propositions. If we are considering the special case of so-called 'singular' (or object-dependent) propositions, to be examined below, then it is natural to move from one to the other. But nonetheless the ideas are distinct: one could consistently deny that intentionality is a relation to intentional objects and yet maintain that it can involve relations to propositions of some kind. This might mean, for example, that intentional states have a structure which can be analysed in various ways. For instance, one can distinguish within a propositional attitude the attitude type (belief, hope etc.) from the specific content of the attitude. ${ }^{8}$ And one can hold this together with the denial that intentionality is essentially a relation to its objects. In the case of perception, this means that experiences are not essentially relations to the object of experience: what is seen, touched, smelled etc.. And since it would be absurd to think that a proposition is the object of an experience in this sense, the thesis that intentional

\footnotetext{
${ }^{8}$ More generally, we can distinguish between what I call, following Searle (1983) intentional mode and intentional content (Crane 2001: 28-33). This is the distinction Husserl expresses as the distinction between intentional quality and intentional matter (Husserl 1900/1901: 233).
} 
states are 'relations to propositions' is consistent with the thesis that they are not relations to their objects. So an intentionalist theory of perception, on this understanding, says that perceptual representation is intrinsic to the perceptual state itself that it represents the world, even if the state is one which can be analysed into its various components. ${ }^{9}$

Some philosophers, however, will deny that intentionality or representation is non-relational: externalists about intentionality or mental content will say that some intentionality is genuinely relational. They will say that some representations are relational and others are not. Hence they will say that some intentionality is relational and some is not. Of course, I cannot object to someone who decides to use the term 'intentionality' in this way; the important thing here is not which words one uses but which ideas and distinctions among ideas one is trying to express. Nonetheless, I doubt whether this is the most helpful way to use the terminology of intentionality in this context. For it seems to me extremely obscure how one of the fundamental characteristics of the mind (or, indeed, anything) could, in itself, be sometimes a relation, and sometimes not. But I will not address this issue directly here. Instead, I will briefly address the question of whether such a 'mixed' view of intentionality can properly accommodate the distinction I am drawing (to use Campbell's words) between relational and representational views of experience.

\footnotetext{
${ }^{9}$ This characterisation of the intentionality of perception differs from that recently offered by Alex Byrne (2001). Byrne describes intentionalism about perception as the view that the propositional content of perceptual experiences in a particular modality (for example, vision) determines their phenomenal character. In other words: there can be no difference in phenomenal character without a difference in content' (Byrne 2001: section 2; see also Tye 2000: 45). Byrne takes intentionalism so characterised to be compatible with both a version of the sense-data theory and with disjunctivism (2001: fn 7, and end of section 1). This is because he thinks that these theories all hold that perception has a representational propositional content; they just differ over what the content exactly concerns or is about. Therefore the only non-intentional theories of perception are (a) the adverbial theory and (b) the qualia theory. This way of thinking is initially appealing: indeed, I accepted something like it myself in chapter 5 of Crane 2001; but I now think this way of thinking about perception misrepresents the essence of the intentional theory, since it does not make the significant distinction between the relational and representational views of experience.
} 
The mixed view says that this is best accommodated by the distinction between object-dependent and object-independent intentional contents or states. An object-dependent intentional state is one whose existence depends on the existence of a particular object; an object-independent state is one whose existence does not. So the idea is that a representational conception of experience must employ an objectindependent conception of intentional states, and a relational conception must employ an object-dependent conception. However, the first of these claims is not true: as Burge (1991) has shown, a representational theory of perception can allow that particular episodes of perceiving are object-dependent in character. On Burge's theory, hallucination and perception have the same content, and hence are states of the same fundamental kind, even though the specific nature of a particular episode of perceiving may involve the existence of a particular object. We need to distinguish between what is true of the individual episode of perceiving and what is true of states belonging to that same fundamental kind (see Martin 2003 for a detailed defence of this distinction).

But even if the representational conception does not have to employ an objectindependent conception of mental states, couldn't the essence of the relational conception be expressed by the idea of an object-dependent intentional state? The answer to this question is complex. First, it should be pointed out that the very idea of an object-dependent state of mind is not sufficient to account for genuine perception as the relational conception understands it. For object-dependent states of mind, if there are any such things, might be object-dependent for many reasons: maybe because they are essentially expressed using proper names; or maybe because they concern 'natural kinds'; or maybe because they exploit some causal link to the object of thought. In all of these cases, the existence of the particular state of mind is 
dependent on the existence of an object. But in none of them is the object present to the mind in the way which the relational conception says objects are present to the mind in perception. What is distinctive of this presence to the mind we find in perception? The defender of the mixed view may answer that what is distinctive of perception is that the specific kind of intentional act required is an act with a demonstrative content: thoughts with content of the form that is $F$ or that $F$ is $G$. The idea is then that the relational conception of perceptual experience will give an account of the object-dependent intentionality of perception in terms of the subject's capacity to have demonstrative thoughts about the objects perceived.

This is a plausible thing for the defender of the mixed view to say. But notice that it is making a claim about the distinctive content of perception depend on a claim about the distinctive kinds of demonstrative thoughts which perception makes available. As Campbell has argued, there is a more fundamental question: what is it for perception to make something available for thought in the first place? And here I think we get a better understanding of the sense in which perception is relational if we ask, not about the contents of thoughts based on perception, but about perception itself (see Campbell 2002). The fundamental idea behind the relational view of perception is that perception somehow makes the world itself manifest to the mind. To understand this idea better we should suspend this talk of object-dependent thoughts and try and locate the real heart of the relational conception of perceptual experience.

\section{Disjunctivism}

The theory which best accommodates the relational conception of perceptual experience is the disjunctivist theory. Disjunctivism is best seen as a response to the problem of hallucination which attempts to do justice to the fact that in genuine 
perception the objects of experience are present to the mind in a way in which they can never be in thought. In attempting to do justice to the sense in which the world itself - and not just a representation of it, even an object-dependent representation of it - is present to the mind in perception, disjunctivism proposes that different accounts should be given of genuine perception and hallucination. Disjunctivism makes the possibility of hallucination compatible with the relationality of perception by denying that the hallucination and the subjectively indistinguishable perception are states of the same fundamental psychological kind. The theory denies therefore that subjective indistinguishability of experiences is sufficient for them to be of the same fundamental kind.

By denying this, disjunctivism does not deny that there is some true description under which both the perception, say, of a rabbit and a subjectively indistinguishable hallucination of a rabbit can fall. It is easy to provide such a true description: both experiences are experiences which are subjectively indistinguishable from a perception of a rabbit. Disjunctivists do not deny that there is such a true description. What they deny is that what makes it true that these two experiences are describable in this way is the presence of the same specific kind of mental state in the case of perception and hallucination. In the case of the perception, what makes it true that the description applies is that the experience is a perception of a rabbit; in the hallucinatory case, what makes it true that the description applies is that the experience is a hallucination of a rabbit. What the disjunctivist therefore rejects is what J.M. Hinton calls "the doctrine of the "experience" as the common element in a given perception' and an indistinguishable hallucination (Hinton 1973: 71). The most specific common description of both states, then, is a merely disjunctive one: the 
perceptual appearance of a rabbit is either a genuine perception of a rabbit or a mere hallucination of a rabbit. Hence the theory's name. ${ }^{10}$

Disjunctivism is sometimes misunderstood, by its friends as well as by its enemies. In his endorsement of the theory, Putnam argues that its distinctive claim is 'that there is nothing literally in common' in perception and hallucination, 'that is, no identical quality' (1999: 152). But this cannot be right. For as we have just observed, disjunctivists do say that there is something literally in common between a perception of an $X$ and a hallucination of an $X$ - each state is subjectively indistinguishable from a perception of an $X$ - and to that extent they exhibit a common 'quality'. As McDowell says, 'the uncontentiously legitimate category of things that are the same across the different cases is the category of how things seem to the subject'

(McDowell 1987: 157). But what the members of this category have in common is not that they are all the same kind of experience. It is rather that to be a member of this category, a state of mind merely has to satisfy a disjunctive condition of the kind described in the previous paragraph. ${ }^{11}$

Disjunctivists need not deny either that there is a common physical state - for example, a brain state - shared by the perceiver and the hallucinator. What they will deny is that the state of perceiving an object is identical with, or supervenes upon, this physical state. This is because perceiving an object is an essentially relational state, of

\footnotetext{
${ }^{10}$ The theory was first proposed by Hinton (1973) and was later developed by P.F. Snowdon (1979), John McDowell (1982 and 1987) and M.G.F. Martin (2002, forthcoming). It has recently been endorsed by Hilary Putnam (1999) and Timothy Williamson (2000).

${ }^{11}$ Putnam thinks, however, that there is an argument against the view that there is anything in common between perception and hallucination. Hallucinations are defined as states of mind which are subjectively indistinguishable from perceptions. But, he argues, subjective indistinguishability cannot define a condition for the identity of mental states since (as reflection on the so-called 'phenomenal sorites' shows) subjective indistinguishability is not transitive whereas identity must be (1999: 130). If Putnam's argument were sound, then it would show that there can be no common identical condition or state, defined simply in terms of subjective indistinguishability, in hallucination and perception. But as we have seen, the existence of such a state or condition is a consequence of the definition of hallucination in this context; so everyone, disjunctivists included, must accept it. So there must be something wrong with Putnam's argument; for myself, I am persuaded by Graff 2001 that subjective indistinguishability is, contrary to widespread opinion, transitive.
} 
which the object perceived is a constituent; so the perception is constitutively dependent on the object perceived. Whereas the intentionalist sees the qualities presented in perceptual experience as represented, the disjunctivist sees these qualities as instantiated in perception, and as merely represented in hallucination (Martin 2002: 392-5). This is why disjunctivists sometimes argue that only by treating qualities as instantiated in this way can we do justice to the sense in which perception is the presentation as opposed to the representation of the things perceived (see the discussion in Searle 1983: 45-6 and the commentary on this in McDowell 1994b). For this reason, it seems to me preferable not to say that the relationality of perception is best captured, according to this view, by a special kind of relational (or objectdependent) 'representational content'. Rather, the key idea is this: the phenomenal character of a genuine perception is determined by how the perceived world is.

The essence of the disjunctivist view, on the present understanding, is its attempt to preserve the genuine relationality of perception. As we saw at the beginning of this paper, that perceptual experience is a genuine relation to its objects seems at first like the most obvious fact about experience. It is easy to see how it lies behind Strawson's claim about our ordinary descriptions of experience, and behind the positive claim of the transparency thesis. So to preserve this relationality would be to preserve one of the central features of perception as we experience it - part of the commonsense conception, if you like. Disjunctivists preserves this feature by denying something which is not (they claim) so obviously part of the commonsense conception of perception: that conscious states which are subjectively indistinguishable are states of the same fundamental, determinate or specific kind. So it is wrong to say, as Tye (2000) does, that disjunctivism can be rejected because it is contrary to commonsense. Rather, the view is attempting to preserve what seems to be 
one of the most obvious or commonsense features of perception - its relationality - in the face of the challenge from the argument from hallucination. The price it pays for this is that it cannot count subjectively indistinguishable states of mind as states of the same fundamental kind, and therefore it imposes limits on what can be known about the nature of experience from the subjective perspective; in other words, limits on authoritative introspective self-knowledge (Martin 2003). These limits should not, however, come as a surprise to anyone tempted by externalist conceptions of the mind. For despite the continued debate about the compatibility of externalism and authoritative 'self-knowledge', it is arguably part of the essence of externalism that it imposes limits on what can be known about the mind through introspection (Farkas 2003).

The intentionalist view also comes with a price. For it must deny that perceptual experience is a relation. When one does succeed in perceiving an object, one is related to it, of course; but this relation is not essential to the perceptual experience being of the fundamental kind that it is. In a certain sense, then, critics of intentionalism are right when they say that on the intentionalist view, perception 'falls short' of the world, and in this sense creates what Putnam calls an 'interface' between the mind and the world. The essence of perception - perceptual experience itself does fall short of the world. But according to the intentionalist, this is not something which should create any metaphysical or epistemological anxiety; it is simply a consequence of a general aspect of intentionality as traditionally conceived.

\section{The question of qualia}


Where does this discussion of the intentionalist and disjunctivist theories leave the question of qualia? To answer this question, I need to step back and recapitulate some of the points I have been trying to make here.

One reason we are provoked to offer a philosophical theory or account of some phenomenon is that the phenomenon is itself intrinsically puzzling, or because some argument is constructed to demonstrate that it is problematic or even impossible. So it is, I have argued, with philosophical theories of perception. The sense-data, intentionalist and disjunctivist theories of perception are attempts to answer the apparent contradictions found within the phenomena of perception when we consider certain actual or possible perceptual scenarios. Without challenges like this, it is somewhat hard to see why we would need a philosophical theory of perception at all. I argued in section 2 that the transparency claims brought to light two questions: (i) how should we account for what we see when we see what isn't there? And (ii) how should we account for those properties instantiated in experience which are not properties of objects of experience? In section 3, I showed how these two questions lie behind the arguments from hallucination and illusion, and how the main theories of perception are best seen as responding to these problems. Sections 4 and 5 described in a bit more detail what the conflict between these theories of experience - the disjunctive and the intentionalist theories -really amounts to. I claim that the fundamental disagreement is about whether there is a perceptual relation.

Where does the qualia theory fit into this conception of the problems of perception? One possible place might seem to be that occupied by the adverbial theory. The adverbial theory says that when it seems that a perceived object is $F$ even though it is not, the experience has the property of being a sensing $F$-ly. The theory can then use this account to answer the argument from hallucination: the objects one 
is aware of in hallucination are really modifications of one's own experience. Regardless of its plausibility, the adverbial theory is an intelligible response to the problems of perception as described here.

But today's qualia theory is not the adverbial theory. The qualia theory typically accepts that perception exhibits intentionality, that it has intentional content. But it holds that this cannot account for the entire phenomenal character of perceptual experience (Block 1996; Peacocke 1983: chapter 1). Hence it does not try to explain all aspects of what is given in experience in terms of qualia; only the 'qualitative' aspects. We need not embark on a discussion of what 'qualitative' means here; we need only observe that while it is often said that there are 'red qualia' or 'sour taste qualia', few qualia theorists these days will say there are tomato qualia or round qualia. The adverbial theory, on the other hand, did attempt to explain all aspects of what is given in experience in terms of properties of experience: this is because it was responding - however unsuccessfully - to the problems posed by the arguments from illusion and hallucination. Today's qualia theory, by contrast, does not seem to be a direct response to these problems.

It may be said here that this objection is purely ad hominem: even if today's qualia theory does not actually go all the way with the adverbial theory, what is stopping it from doing so? That is, why shouldn't the qualia theory attempt to explain all features of what it is like to have an experience in terms of intrinsic, nonintentional qualities of experience? The simple answer to this is that if it did this - and became a real adverbial theory - then it would cease to have any plausibility at all. There are familiar reasons why the adverbial theory is indefensible (see Jackson 1977) and their source can be traced back to the theory's failure to accommodate even the 
apparent relationality of perception (see Martin 1998; Crane 2000). So it is central to any plausibility the qualia theory has that it is not identical with the adverbial theory.

As it is normally formulated, then, the qualia theory is best seen as a form of intentionalism: the idea is that in addition to an experience's having representational content, the experience also has qualia. As explained in section 1, this claim is not simply the denial of representationalism. That is, it is not just the view that one can be aware of how one's experience is, as opposed to how the objects of experience are. I argued in section 2 that this view is very plausible, and that Tye's representationalism is therefore false. One can be aware, for example, that one is seeing something, and the fact that one is seeing something (as opposed to hearing it) is not itself a fact about the objects of one's experience (see Block forthcoming). Rather, it is an introspectible fact about the experience itself. The same is true of the case of seeing blurrily. However, these facts do not have to be understood in terms of the instantiation of intrinsic qualia. This is a further claim, which needs further argument. ${ }^{12}$

Disjunctivists and intentionalists should both deny Tye's representationalism for the reason just given. But since disjunctivists reject the idea that perceptual experience can be given an intrinsic qualitative characterization, they will accordingly reject the idea that experience involves qualia: the only characterization of a genuine, veridical, perceptual experience is a relational one; and the only experiential way of characterizing the hallucinatory experience is as a mental episode which is subjectively indistinguishable from a veridical experience. If there were qualia, then there would be a further common characterization of the perception and the

\footnotetext{
${ }^{12}$ To give an illustration of how you can deny representationalism while denying qualia: an intentionalist about perception might want to say that what one is aware of in these cases is something like the intentional mode (Crane 2001: 143-4) rather than visual field qualia like Peacocke's (1983) 'primed predicates'.
} 
hallucination in terms of their common intrinsic nature. Since the disjunctivist holds that there is no such thing, disjunctivists must reject qualia.

The upshot is that the debate about qualia should be seen as an in-house dispute among intentionalists. If they reject Tye's representationalism, then intentionalists may still want to argue about whether there are qualia. But whatever are the reasons on either side of this argument, they do not spring from the debates at the heart of the philosophy of perception, understood in terms of the traditional problems of illusion and hallucination. For adopting the qualia theory does not advance these debates, and nor does denying it. This is because these debates turn fundamentally on the question of whether there is a perceptual relation, and the qualia theory simply fails to engage with that question. Far from creating a chasm in the philosophy of perception, then, the question of qualia does not even make a small crevasse. $^{13}$

Department of Philosophy, University College London Gower Street, London WC1E 6BT, UK

\section{References}

Anscombe, G.E.M. (1965), 'The Intentionality of Sensation: a Grammatical Feature' in R.J. Butler (ed.), Analytical Philosophy: First Series (Oxford: Blackwell); reprinted in her Metaphysics and the Philosophy of Mind: Collected Papers, Vol. II. (Oxford: Blackwell); also in Noë and Thompson (eds.) 2002.

Austin, J.L. (1962), Sense and Sensibilia (Oxford: Oxford University Press). Block, Ned (1996), 'Mental Paint and Mental Latex', in E. Villanueva (ed.), Philosophical Issues 7 (Atascadero, CA: Ridgeview): 19-49.

Block, Ned (1997), 'Inverted Earth' in N. Block, O. Flanagan and G. Güzeldere (eds.), The Nature of Consciousness (Cambridge, MA: MIT Press).

Block, Ned (forthcoming), 'Mental Paint', in M. Hahn and B. Ramberg (eds.), Others

\footnotetext{
${ }^{13}$ Earlier versions of this paper were presented at ELTE in Budapest, the University of York, the Joint Session of the Mind Association and the Aristotelian Society at Belfast in 2003, the University of Massachusetts at Amherst, Tufts University and the Centre for Subjectivity Research in Copenhagen. Thanks to the participants on these occasions, and especially to Alex Byrne, Stephen Everson, Katalin Farkas, Howard Robinson, Jonathan Schaffer, Susanna Siegel, Hong Yu Wong, Dan Zahavi and an anonymous referee for OUP for their comments. I am especially grateful to Tamar Gendler and John Hawthorne for their detailed and insightful comments on the penultimate version. This paper was written while I was a fellow of the Collegium Budapest, during a period of leave sponsored by the AHRB's Research Leave Scheme.
} 
on Burge: 10 Essays With Responses From Tyler Burge (Cambridge, MA: MIT Press).

Broad, C. D. (1923), 'The Theory of Sensa' in Swartz 1965.

Burge, Tyler (1991), 'Vision and Intentional Content' in E. LePore and R. Van Gulick (eds.), John Searle and his Critics (Oxford: Blackwell): 195-213.

Byrne, Alex (2001), 'Intentionalism Defended', Philosophical Review 110:199-240.

Campbell, John (2002), 'Berkeley's Puzzle' in Tamar Szabó Gendler and John Hawthorne (eds.), Conceivability and Possibility (Oxford: Oxford University Press).

Campbell, John (2003), Reference and Consciousness (Oxford: Oxford University Press).

Chalmers, David (1996), The Conscious Mind (Oxford: Oxford University Press).

Chisholm, Roderick M. (1957), Perceiving: A Philosophical Study (Ithaca: Cornell University Press).

Crane, Tim and Sarah Patterson (eds.) (2000), History of the Mind-Body Problem (London: Routledge).

Crane, Tim (ed.) (1992), The Contents of Experience (Cambridge: Cambridge University Press).

Crane, Tim (2000), 'The Origins of Qualia' in Crane and Patterson (2000).

Crane, Tim (2001), Elements of Mind (Oxford: Oxford University Press).

Dancy, Jonathan (ed.) (1988), Perceptual Knowledge (Oxford: Oxford University Press).

Ducasse, C. J. (1942), 'Moore's Refutation of Idealism', in P. A. Schilpp (ed.) The Philosophy of G. E. Moore (Evanston, IL: Library of Living Philosophers, now published by Open Court, La Salle, IL.).

Farkas, Katalin (2003), 'What is Externalism?', Philosophical Studies 112: 187-208. Graff, Delia. (2001), 'Phenomenal Continuua and the Sorites', Mind 110: 905-935. Harman, Gilbert. (1990), 'The Intrinsic Quality of Experience', in J. Tomberlin (ed.) Philosophical Perspectives 4 (Atascadero: Ridgeview); reprinted in Block, Ned; Flanagan, Owen and Guzeldere, Guven (eds.) (1997) The Nature of Consciousness (Cambridge, MA: MIT Press).

Heidegger, Martin. (1935), 'The Origin of the Work of Art' in D. Farrell Krell (ed.) (trans.), Martin Heidegger: Basic Writings (New York: Harper and Row, 1977).

Hilbert, David R. and Mark Eli Kalderon (2000), 'Color and the Inverted Spectrum' in S. Davis (ed.), Color Perception: Philosophical, Psychological, Artistic and Computational Perspectives (New York and Oxford: Oxford University Press).

Hinton, J. M. (1973), Experiences (Oxford: Clarendon Press).

Jackson, Frank (1977), Perception: A Representative Theory (Cambridge: Cambridge University Press).

Johnston, Mark (2004), 'The Obscure Object of Hallucination', Philosophical Studies 120:113-183.

Kind, Amy (2003), 'What's So Transparent About Transparency?' Philosophical Studies 115: 225-244.

Loar, Brian (2002), 'Transparent Experience' in A. Jokic and Q.Smith (eds.), Consciousness: New Philosophical Perspectives (Oxford: Oxford University Press).

Martin, M.G.F. (1995), 'Perceptual Content' in S. Guttenplan (ed.) A Companion to the Philosophy of Mind (Oxford: Blackwell). 
Martin, M.G.F. (1998), 'Setting Things Before the Mind' in A. O'Hear (ed.) Contemporary Issues in the Philosophy of Mind (Cambridge: Cambridge University Press).

Martin, M.G.F. (2000), 'Beyond Dispute: Sense-Data, Intentionality and the MindBody Problem', in Crane and Patterson (eds.) (2000).

Martin, M.G.F. (2002), 'The Transparency of Experience', Mind and Language 17: 376-425.

Martin, M.G.F. (2003), 'Particular Thoughts and Singular Thought' in A. O'Hear (ed.) Thought and Language (Cambridge: Cambridge University Press).

Martin, M.G.F. (2004), 'The Limits of Self-Awareness', Philosophical Studies 120: 37-89.

McDowell, John. (1982), 'Criteria, Defeasibility \& Knowledge', Proceedings of the British Academy 1982: 455-79. Reprinted in Dancy (ed.) (1988).

McDowell, John. (1986), 'Singular Thought and the Extent of Inner Space', in Pettit and McDowell (eds.) (1986); reprinted in McDowell (1998).

McDowell, John. (1994a), Mind and World (Cambridge, Mass.: Harvard University Press).

McDowell, John. (1994b), 'The Content of Perceptual Experience', Philosophical Quarterly 44: 190-205; reprinted in Noë \& Thompson (eds.) (2002).

McDowell, John. (1998), Meaning, Knowledge and Reality (Cambridge, MA: Harvard University Press).

Noë, Alva. and Evan Thompson (eds.) (2002), Vision and Mind: Selected Readings in the Philosophy of Perception (Cambridge, Mass.: MIT Press).

Peacocke, Christopher (1983), Sense and Content (Oxford: Oxford University Press).

Pettit, Philip and John McDowell (eds.) (1986), Subject, Thought and Context (Oxford: Clarendon Press).

Pitcher, George (1970), A Theory of Perception (Princeton: Princeton University Press).

Price, H. H. (1932), Perception (London: Methuen).

Putnam, Hilary (1999), The Threefold Cord (New York: Columbia University Press).

Robinson, Howard (1994), Perception (London: Routledge).

Searle, John (1983), Intentionality (Cambridge: Cambridge University Press).

Shoemaker, Sydney (1975), 'Functionalism and Qualia', Philosophical Studies 27: 291-315.

Shoemaker, Sydney (1990), 'Qualities and Qualia: What's in the Mind?', Philosophy and Phenomenological Research 50, Supplement: 109-31.

Siewert, Charles. (2003), 'Is Experience Transparent?', Philosophical Studies 117: $15-41$.

Smith, A. D. (2002), The Problem of Perception (Cambridge, Mass.: Harvard University Press).

Snowdon, P. F. (1979-80), 'Perception, Vision and Causation', Proceedings of the Aristotelian Society 81: 175-192.

Snowdon, P.F. (1990), 'The Objects of Perceptual Experience', Proceedings of the Aristotelian Society Supplementary 64: 121-150

Stoljar, Daniel (forthcoming), 'The Argument from Diaphonousness', Canadian Journal of Philosophy.

Strawson, P.F. (1979), 'Perception and its Objects' in G. Macdonald ed. Perception and Identity: Essays Presented to A.J. Ayer with His Replies (London: Macmillan); Page references to reprint in Noë and Thompson (eds.) (2002). 
Swartz, R. J. (1965), Perceiving, Sensing and Knowing (Los Angeles and Berkeley: University of California Press).

Thau, Michael (2002), Consciousness and Cognition (Oxford: Oxford University Press).

Tye, Michael (1992), 'Visual Qualia and Visual Content' in Crane (ed.) (1992).

Tye, Michael (1995), Ten Problems of Consciousness (Cambridge, MA: MIT Press).

Tye, Michael (2000), Consciousness, Color and Content (Cambridge, MA: MIT Press).

Williamson, Timothy (2000), Knowledge and its Limits (Oxford: Oxford University Press). 